Proceedings

\title{
Development of formulation based on essential oils of rose- mary to manage pests of stored cereal foodstuffs ${ }^{\dagger}$
}

\author{
Abir Soltani ${ }^{1, *}$, Amina Labidi ${ }^{2}$ and Jouda Mediouni Ben Jemâa ${ }^{1}$ \\ 1. Carthage University, National Agricultural Research Institute of Tunisia (INRAT), LR11INRAT06 Labora- \\ tory of Biotechnology Applied to Agriculture, Tunis, Tunisia; joudamediouni1969@gmail.com \\ 2. Jendouba University, Higher Institute of Biotechnology of Beja; LAbidiamina333@gmail.com \\ * Correspondence: soltany.abyr@gmail.com; Tel.: +21696486576 \\ + Presented at the 1st International Electronic Conference on Entomology (IECE 2021), 1-15 July 2021; \\ Available online: https://iece.sciforum.net/.
}

Citation: Soltani, A.;Labidi A.; Mediouni Ben Jemâa, J. Development of formulation based on essential oils of rosemary to fight against pests of stored cereal foodstuffs, in Proceedings of the 1st International Electronic Conference on Entomology, 1-15 July 2021, MDPI: Basel, Switzerland, doi:10.3390/IECE-10407

Published: 30 June 2021

Publisher's Note: MDPI stays neutral with regard to jurisdictional claims in published maps and institutional affiliations.

Copyright: (c) 2021by the authors. Submitted for possible open access publication under the terms and conditions of the Creative Commons Attribution (CC BY) license (http://creativecommons.org/licenses /by/4.0/).

\begin{abstract}
The aim of this work is to evaluate the insecticidal activity of the encapsulatedrosemary (Rosmarinus officinalis L.) essential oil coated intochitosan matrix. The effectiveness of crude and encapsulated oils has been studied during different storage periods (30, 45 and 60 days). Results revealed that the chitosan-essential oil formulation exhibited high insecticidal activity against adults of Tribolium castaneum as compared to crude essential oil during the different storage periods.
\end{abstract}

Keywords: Rosmarinus officinalis; Tribolium castaneum; Chitosan

\section{Introduction}

Cereal production has been considered an important component of Tunisia agriculture [1]. Despite, the developpement efforts made by the authorities in this sector, Tunisian cereal still confronted to various problems [2] such as diseases [3] and insect pests [4]. Various species caused damage toward different stored products [5]. The use of chemical insecticides is one of the most known control methods for postharvest protection, due to its effectiveness [6]. However, previous researches indicated the undesirable effects of several chemical pesticides [7]. Thus, alternatives methods are well needed, which are more respectful to health and environment [8]. In this context, the valorization of plants extracts and essential oils [9] known by several bioactivities like fungicide, microbial and insecticides are required [10].

This work aims to provide innovative and appropriate methods for the control of insect pests of foodstuffs during storage, as well as, to restrict or eliminate the use of chemical insecticides.

\section{Material and methods}

\subsection{Plant material}

Rosmarinusofficinalis was collected from the arboretum Korbos $\left(846 \mathrm{~m} 36^{\circ} 48^{\prime} 54^{\prime \prime} \mathrm{N}\right.$ $1034^{\prime} 14^{\prime \prime}$ E), north Tunisia. The collected samples were air-dried at ambient laboratory conditions.

\subsection{Essential oil (EO) extraction}

Essential oils were extracted by hydrostillation of $150 \mathrm{~g}$ of dried leaves using a modified Clevenger-type apparatus for $4 \mathrm{~h}$ as described by [11]

\subsection{Insect rearing}

T. castaneum was reared on semolina. The rearing conditions were $25 \pm 1{ }^{\circ} \mathrm{C}$, a relative humidity of $65 \pm 5 \%$ and a photoperiod of $12 \mathrm{~h} \mathrm{Light} / 12 \mathrm{~h}$ dark. The boxes were observed 
daily to collect adults according to their age group. Newly emerged adults (7 days old) were used for the bioassays.

\subsection{Preparation of the Chitosan-essential oil formulation}

The used method consists of diluting $4 \mathrm{ml}$ of R.officinalis oil in $40 \mathrm{ml}$ of acetone. This solution was mixed with $40 \mathrm{~g}$ of powder (containing $20 \mathrm{~g}$ of gum Arabic and $20 \mathrm{~g}$ of chitosan). After 5 min of manual stirring, the mixture was placed in a water bath at $30{ }^{\circ} \mathrm{C}$ until the complete evaporation of acetone (obtaining a dry flavored powder). Likewise, a suspension of the powder mixture (gum Arabic + chitosan) with $40 \mathrm{ml}$ of acetone without essential oil was also prepared to serve as a control.

The flavored powders were stored in brown bottles and tightly closed using parafilm and placed in the refrigerator at $4^{\circ} \mathrm{C}$.

\subsection{Characterization of the formulation}

\subsubsection{Encapsulation Efficiency (EE) and Loading Capacity (LC)}

The percentages of EE and LC were determined according to the method described by Woranuch and Yoksan[12]with some modifications, $10 \mathrm{mg}$ of flavored dry chitosangum Arabic was mixed with a solution of hydraulic acid $(\mathrm{HCl})(2 \mathrm{M}, 4 \mathrm{~mL})$ and boiled at $95^{\circ} \mathrm{C}$ for $30 \mathrm{~min}$. Two $\mathrm{ml}$ of ethanol was added after cooling. Then, the mixture was centrifuged at $24,000 \mathrm{rpm}$ for 30 minutes at $4{ }^{\circ} \mathrm{C}$ to separate the loaded pellet from the aqueous solution. One $\mathrm{ml}$ of supernatant was measured by spectrophotometer at $285 \mathrm{~nm}$. A blank was prepared from chitosan-gum Arabic prepared without essential oil. The amount of essential oil charged was calculated from a calibration curve prepared with $R$. officinalis oil in $95 \%$ ethyl alcohol (Abs $=006$ [conc] $\left.+0.220 ; R^{2}=0.577\right)$. Each sample was measured three times.

\subsubsection{Bioassays of the insecticidal activity of the Chitosan-EO and non-encapsulated EO}

For free and encapsulated essential oil, the test consists of introducing 1 adult for each $10 \mathrm{~g}$ of substrate into glass bottle of $1000 \mathrm{~mL}$ volume containing $420 \mathrm{~g}$ of semolina. The oil was deposit using a micropipette on disks of filter paper $7.5 \mathrm{~cm}$ of diameter (Whatman $\mathrm{N}^{\circ} 1$ paper) with the concentration $245.82 \mu \mathrm{L} / \mathrm{L}$ air. For encapsulated essential oil the fumigation test was carried out, of which $3.4 \mathrm{~g}$ and $1.75 \mathrm{~g}$ of chitosan-EO capsule were usedrespectively against $T$. castaneum. The capsules were put in a thin tissue which is then glued to the wall of the jar which is closed hermetically. Each test has 3 replicates. Untreated tests serving as a control were maintained under the same conditions. Mortality assessment was carried out after 30, 45 and 60 days of exposure.

\subsection{Statistical analyzes}

Data were analyzed using SPSS software (version 20). The analysis of variance was carried out according to the GLM (General Linear Models) procedure and the comparison of the means was carried out by the Duncan test at the 5\% probability threshold. Data were arranged according to the independent variables: treatment, and storageperiod. The dependent variable was the $T$. castaneumadult mortality rate.

\section{Results}

\subsection{Encapsulation efficiency (EE) and loading capacity (LC)}

Table 1presented the encapsulation efficiency and loading capacity of the two ratios chitosan: essential oil: 1: 0.5 and 1: 0.2 .

Table 1.Encapsulation efficiency (EE) and loading capacity (LC) of Rosmarinus officinalis essential oil measured by spectrophotometer (UV).

\begin{tabular}{|c|c|c|}
\hline Chitosan: EO (P/P) & EE (\%) & $\mathrm{CC}(\%)$ \\
\hline Ratio .1.0:0.5. & 35.8 & 2.49 \\
\hline
\end{tabular}


The encapsulation efficiency (EE) and loading capacity (CC) for the essential oil of $R$. officinalis encapsulated in a chitosan matrix have been presented in Table 1. In this work, the average value of the EE was $35.8 \%$. Further, the results indicated that the CC value reached $2.49 \%$.

\subsection{Mortality evaluation of insects treated with chitosan-essential oil and crude essential oil}

Figure 1 shows the mortality percentages of adults of T.castaneum after 30, 45 and 60 days of storage periods exposed to crude and encapsulated essential oil.

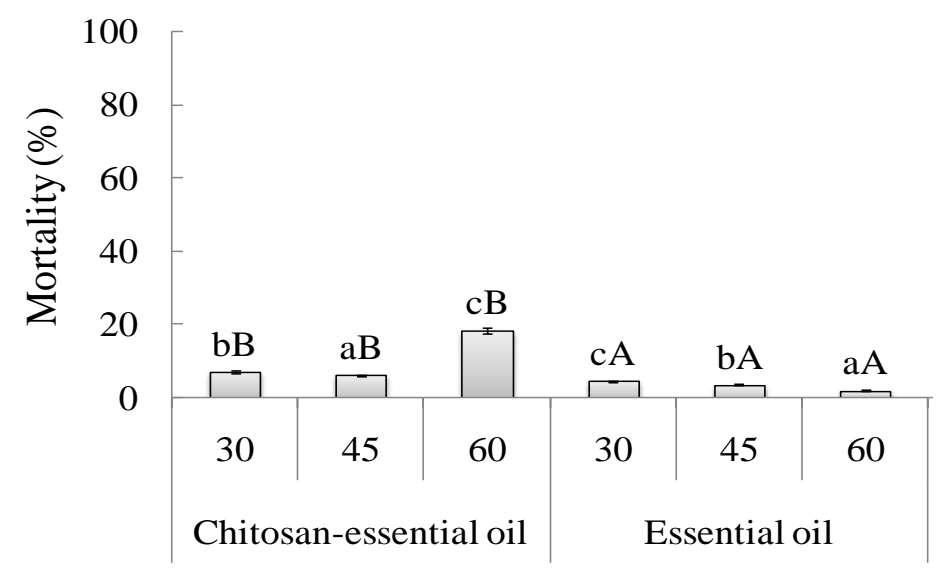

Figure 1. Mortality (\%) of Tribolium castaneum adults caused by Rosmarinusofficinalis essential oil, encapsulated chitosan-essential oil and chemical treatment

Results show that the mortality rate varies depending on the storage period. The mortality rate of $T$. castaneum during the three storage periods (30, 45 and 60 days) varies between $8 \%$ and $20 \%$ for encapsulated essential oil against 6.7 and $2.1 \%$ for crude rosemary oil, which shows the effectiveness of the formulation over time.

From the results, we can notice a strong resistance of T. castaneumagainst essential oil compared to chitosan-essential oil.Statistical analyzes indicate significant differences between the different storage periods $(\mathrm{F}=19.5 ; \mathrm{df}=2 ; \mathrm{P}=0.000)$. Similarly, the results reveal highly significant differences between the two treatments $(\mathrm{F}=4374.00 ; \mathrm{df}=1 ; \mathrm{P}=0.000)$.

\section{Discussion}

Essential oils could be efficient alternatives to conventional fumigants because of their toxicity against insect pests of stored products [13]. However due to their fast degradability properties [14], other appropriate methods are well needed such as encapsulation. Based on these results, the formulation chitosan-essential oil showed encapsulation efficiency with $35.8 \%$ for the ratio 1.0:0.5. In accordance with this study [15] reported that encapsulation efficiency of chitosan-essential oil was $37.87 \%$. However, the nanogels based on chitosan and cachew gum at the ratios matrix: oil 10:2, gum: chitosan 1:1 showed high encapsulation efficiency (70\%). On the other hand, thiswork indicated that mortality of adults caused by chitosan-rosmery essential reached its maximum $20 \%$ after 60 days of storage. Nevertheless, the extension of storage period causes the decrease of the toxicity of essential oil. These results are in agreement with those of Abada et al. [16] that showed the negative correlation between toxicity of rosemary essential oil against $T$. castaneumand storage period.

\section{Conclusion}

It could be conclude that the insecticidal activity of encapsulated essential oil was more toxic against T. castaneum better than crude essential oil. Thus, formulation by using chitosan matrix may improve the toxicity of essential oil during storage. Additionally, this 
technique is needed to overcome the constraints of essential oils in control of stored products. While, additional experiments are recommended to improve of the encapsulation efficiency and clarify its potential toxicity.

Author Contributions: AbirSoltani Conceptualization, methodology, software, validation, A formal analysis, investigation, data curation, writing - original draft preparation, writing - review and editing, visualization, Amina Labidi resources; JoudaMediouni Ben Jemâa project administration, supervision;. All authors have read and agreed to the published version of the manuscript.

Funding: "This research received no external funding"

Informed Consent Statement: "Informed consent was obtained from all subjects involved in the study"

Conflicts of Interest: “The authors declare no conflict of interest." 


\section{References}

1. Hammami, R., Stambouli, T., Frija, A., Souissi, A., Benalaya, A. Comparative Study of the virtual water consumed by cereals in different bioclimatic areas of Tunisia.J. New Sci. 2014, 44, 2352-2362

2. Ayeb, H., Bush, R. Food Insecurity and Revolution in the Middle East and North Africa: Agrarian Questions in Egypt and Tunisia, $3^{\text {rd }}$ ed.; Anthem Press: UK and USA,2019; pp. 77-189.

3. Belahsen, R., Rguibi, M. Population health and Mediterranean diet in southern Mediterranean countries. Public health nutrition 2006, 9, 1130-1135.

4. Jerraya, A.Principaux nuisibles des plantes cultivées et des denrées stockées en Afrique du Nord: leur biologie, leurs ennemis naturels, leurs dégâts et leur contrôle, $3^{\text {rd }}$ ed.; Climat pub: Tunisia, 2003; pp 415

5. Ndomo, A., Tapondjou, A., Tendonkeng, F., Tchouanguep, F. Evaluation of the insecticidal effect of leaves from Callistemon viminalis (Myrtaceae) against a major bean pest: Acanthoscelidesobtectus(Say)(Coleoptera; Bruchidae). Tropicultura2009, 27, 137143.

6. Bounechada, M., Arab, R. Effet insecticide des plantesMeliaazedarach L.Peganumharmala L. surTriboliumcastaneumHerbst (Coleoptera: Tenebrionidae).Dspace.univ-setif.dz. 2011, 1, 1-6.

7. Regnault-Roger, C., Philogène, B. J., Vincent, C. Biopesticides d'origine végétale. In Tropicoltura, 2nd ed.; J. Vercruysse, Eds., Editions Tec \& Doc: Belgium,2002; Volume 24, pp. 128.

8. Ngamo, T. L., Goudoum, A., Ngassoum, M. B., Ngassoum, M., Lognay, G., Malaisse, F., et al. Chronic toxicity of essential oils of 3 local aromatic plants towards Sitophilus zeamaisMotsch (Coleoptera: Curculionidae). Afr. J. Agric. Res. 2007, 2, $164-167$.

9. Isman, M. B., Machial, C. M. Pesticides based on plant essential oils: from traditional practice to commercialization. Advances in phytomedicine2006, 3, 29-44.

10. Jemâa, J. M. B., Tersim, N.,Toudert, K. T., Khouja, M. L. Insecticidal activities of essential oils from leaves of Laurus nobilis L. from Tunisia, Algeria and Morocco, and comparative chemical composition. J. Stored Prod. Res. 2012, 48, 97-104.

11. Hamdi, S. H., Hedjal-Chebheb, M., Kellouche, A., Khouja, M. L., Boudabous, A., Jemâa, J. M. B. Management of three pests' population strains from Tunisia and Algeria using Eucalyptus essential oils. Ind. Crops and Prod. 2015, 74, 551-556.

12. Woranuch, S., Yoksan, R. Eugenol-loaded chitosan nanoparticles: I. Thermal stability improvement of eugenol through encapsulation. Carbohydrate polymers2013, 96, 578-585.

13. Bachrouch, O., Jemâa, J. M.-B., Wissem, A. W., Talou, T., Marzouk, B., \& Abderraba, M. (2010). Composition and insecticidal activity of essential oil from Pistacia lentiscus L. against Ectomyeloisceratoniae Zeller and Ephestiakuehniella Zeller (Lepidoptera: Pyralidae). J. Stored P. Res. 2010 46, 242-247.

14. Rajendran, S.,Sriranjini, V. Plant products as fumigants for stored-product insect control. J. Stored Prod. Res. $2008,44,126-135$.

15. Ghaderi-Ghahfarokhi, M., Barzegar, M., Sahari, M., Gavlighi, H. A.,Gardini, F. Chitosan-cinnamon essential oil nano-formulation: Application as a novel additive for controlled release and shelf life extension of beef patties. Int. J.Biol. Macro. 2017, 102, $19-28$

16. Abada, M. B., Hamdi, S. H., Gharib, R., Messaoud, C., Fourmentin, S., Greige-Gerges, H., et al. Post-harvest management control of Ectomyelois ceratoniae (Zeller)(Lepidoptera: Pyralidae): new insights through essential oil encapsulation in cyclodextrin. Pest Manag. Sci. 2019, 75, 2000-2008. 